\title{
DỨcin
}

Technological University Dublin

ARROW@TU Dublin

2001-01-01

\section{A Review of the Different Methods for Assessing Standing Balance}

Jacinta Browne

Technological University Dublin, jacinta.browne@tudublin.ie

N. J. O'Hare

St. James's Hospital, Dublin

Follow this and additional works at: https://arrow.tudublin.ie/meduart

Part of the Physics Commons

\section{Recommended Citation}

Browne, J. \& O'Hare, N. (2001). A Review of the Different Methods for Assessing Standing Balance.

Physiotherapy, vol. 87, no.9, pg. 489-495. doi:10.1016/S0031-9406(05)60696-7

This Article is brought to you for free and open access by the Medical Ultrasound at ARROW@TU Dublin. It has been accepted for inclusion in Articles by an authorized administrator of ARROW@TU Dublin. For more information, please contact arrow.admin@tudublin.ie, aisling.coyne@tudublin.ie, gerard.connolly@tudublin.ie.

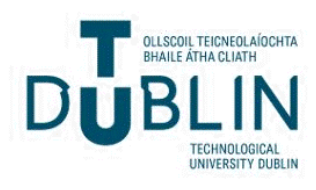




\title{
A Review of the Different Methods for Assessing Standing Balance
}

\author{
Authors: JE Browne and NJ O'Hare
}

Address: Medical Physics \& Bioengineering Department, St. James’s Hospital, James's St., Dublin 8, Ireland.

\begin{abstract}
This paper is a review of the balance assessment methods currently used to evaluate standing balance. Most of the presently available instrumentation appears to be more suited to research laboratories than to routine clinical situations. Functional assessments of balance appear to be the quickest test to administer and do not require expensive equipment however only gross changes in balance can be detected making them suitable as a screening tool for identifying subject's needing more thorough evaluation. Force platforms appear to be most suited balance assessment instrumentation to the clinical situation since it produces a real time display and can detect small changes in subject's ability to maintain their balance making them suitable for thorough evaluations of balance and for monitoring patient's progress.
\end{abstract}

\section{Introduction}

Balance is the ability to maintain equilibrium by positioning our centre of gravity over our base of support. The centre of gravity is the body's centre of mass and it changes according to changes in positions and movements of the body segments (Murray et al, 1975). Postural adjustments occur in order to maintain equilibrium. These postural adjustments which maintain balance are known as equilibrium reactions (Jones et al, 1996. The equilibrium reactions are carried out by a complex process involving afferents from the sensory system, integration of the afferents by the central nervous system (CNS), and the efferents being sent from the CNS to an intact musculoskeletal system (Duncan, 1989). Balance is affected when part of the control system is not working correctly for example if the vestibular system is damaged or if the CNS is not integrating the information correctly. Other factors, which affect balance, are alcohol, drugs and the ageing process.

The fact that balance disorders can occur from a wide range of causes explains the interest from a wide variety of disciplines such as scientists, neurologists, otoneurologists, physical and occupational therapists (Njiokiktjien, 1980; Berg, 1989; Andres and Anderson, 1980; Okubo, 1980; Baloh et al, 1998(b)). This interest in the assessment of standing balance has led to a variety of different techniques for 
measuring balance being developed; functional assessments, sway magnetometry and force platforms. The earliest scientific studies of human standing balance was conducted by Romberg in 1853, who observed diseases of the central nervous system (CNS) by the amount subject's swayed with their eyes closed (Romberg, 1853). The evaluation of balance disorders has an important role for a number of reasons. Firstly, it is an aid to understanding how the postural control system works. Secondly, it is an aid to clinical diagnosis and the assessment of treatment efficacy. Thirdly, it can be used to identify elderly subjects with a history of falls and areas where they are at risk of falling. The aim of this paper is to review some of the current techniques used for assessment of standing balance in relation to their appropriateness of use for specific conditions, also their merits and weaknesses.

\section{The Different Methods Used to Assess Balance}

The methods used to understand the postural control system and measure standing balance have evolved over time. Early studies focused on abnormalities in postural sway as an indicator of balance disorders, and then later studies progressed to more complex laboratory testing of responses under various conditions. By the mid 1980's functional tests of balance started to become more prominent (Berg and Norman, 1996). Due to the complexity of the postural control system, balance can be evaluated at both a functional and a physiological level. The functional level can be more directly assessed by functional performance tests of reach and mobility. The physiological level includes measuring the contribution of sensory, motor and effector components. Under static conditions the postural control system may compensate when disorders occur whereas, during dynamic conditions, compensation is usually delayed or insufficient (Starck et al, 1993). Balance assessment tests should attempt to simulate dynamic conditions in order to stress the postural control system fully and reveal the presence of a balance disorder (Furman, 1994). Balance disorders are more prevalent in elderly subjects, with disorders occurring due to the ageing process or diseases of the CNS, sensory system and occasionally the vestibular system (Tell et al, 1998; Balogun et al, 1994; Baloh et al, 1998(a); Baloh et al 1998(b)). Vestibular balance disorders occur in subjects of all ages and are the most difficult balance disorder to identify and quantify (Baloh et al, 1998(a)). 


\section{Functional Assessment of Standing Balance}

Functional assessment tests are commonly used in clinical practice by doctors and physiotherapists due to the speed with which they can be administered and also due to them rarely requiring expensive equipment (Berg and Norman, 1996).

The Functional Reach test measures the subject's ability to reach as far forward as possible without taking a step forward or falling. This provides quantitative dynamic information about the subject's ability to maintain standing balance, by causing the subject to move their COG towards the edge of their base of support (Duncan et al, 1990). The Functional reach test has been found to have excellent predictive validity of subject's at risk of falls (Duncan et al, 1992). It is mostly used for elderly subjects with balance problems resulting from the ageing process or associated disease such as Parkinson's disease. It is a quick test to administer and is therefore useful as a screening tool which is demonstrated by its routine use in physiotherapy departments. It has been found to be a reliable test with an Inter-rater reliability of ICC $=0.98$ and an Intra-rater reliability of ICC $=0.92$ (Duncan et al, 1990).

The Single Leg Stance Test assesses a subject's ability to maintain balance by standing on one foot with their eyes open and subsequently with their eyes closed, thus significantly reducing their base of support (Gehlsen and Whaley, 1990). This test is more sensitive for assessing normal balance and is not generally used for assessing elderly subjects with suspected balance impairment and is therefore limited in its use. The single leg stance test has only been investigated for inter-subject reliability and it was found to have an ICC $=0.73$ (Hanke, 1992).

The Fugl-Meyer Test contains six sections which assesses the subject's independence by evaluating their joint movement, joint pain, upper extremity motor control, lower extremity motor control, balance and sensation (Fugl-Meyer et al, 1975). A numerical value is obtained for each of the activities in the sections for those performed in and out of synergy. The section for evaluating balance contains three tests for assessing sitting balance and four tests for assessing standing balance, these tasks are graded using a 3-point ordinal scale. This test provides a 
comprehensive qualitative evaluation of functional balance and is commonly used for assessing subject's who have suffered a stroke or subjects with balance disorders as a result of neurological damage, such as Parkinson's disease. There have been no reported studies that have investigated the reliability of this test.

The Fall Risk Index evaluates the independence of chronically disabled patients based on nine risk factor scores (Tinetti et al, 1986). The patient is scored on mobility, hearing, mental status and morale. The mobility score combines a standing balance and gait assessment. Standing balance is assessed by simulating conditions, which are known to contribute to the occurrence of falls in elderly subjects. The Fall Risk Index is used to evaluate subjects who have a history of falls and it identifies areas of particular danger to these subject's. This test includes subsets which assess hearing, mental status and morale because falls which occur in elderly population are not always due to balance disorders but can be due to giddiness and a fear of falling The Fall Risk Index scores for subjects were found to vary by less than $10 \%$ between observers (Tinetti et al, 1986).

The Barthel Index evaluates the independence of chronically disabled patients based on their performance in ten basic activities of daily living, one of which is standing balance (Mahoney and Barthel, 1965). This test is usually used to evaluate the independence of subject's after a stroke. No studies have investigated the reliability of this test for evaluating subject's levels of independence.

The Berg Balance Test evaluates subject's performance in 14 items common in everyday life, these items evaluate the subject's ability to maintain sitting and standing positions of increasing difficulty. Standing balance is evaluated by getting the subject's to use progressively smaller bases of support (Berg et al, 1992). This test was developed specifically for assessing balance while sitting or standing. This test is used to assess elderly subject's with a history of falls, subject's with neurological disorders and subject's who have had a stroke. The Berg Balance test has been found to have an Inter-rater reliability of ICC $=0.98$ and an Intra-rater reliability of ICC $=0.98$ (Berg et al, 1992). 
Other functional tests include the Jebsen Hand Function test (Jebsen et al, 1969), the Postural Stress test (Hill et al, 1990), and the Katz Index (Katz et al, 1963).

Functional balance assessment tests are very successful in identifying the presence of balance disorders or associated disability but are unable to differentiate between levels of impairment. They are unable to detect small objective changes in subjects' ability to balance. Therefore, it is recommended that functional assessments should be used in a screening capacity, but that a more objective balance assessment test should be used for a thorough evaluation of balance.

\section{Physiological Assessment of Balance}

Physiological assessments evaluate balance by measuring the subject's sway, directly by calculating the movement of the subject's centre of gravity (COG) or indirectly by calculating the movement of the subject's centre of pressure (COP). The COP is an approximation of the COG under static or slow moving conditions (Winter, 1995). There are a large number of physiological assessment tests available for measuring balance however, only a few are available commercially the remainder existing only in research laboratories.

Potentiometric Displacement Transducer records the sway patterns of subjects by measuring the displacement at their waist, by using a potentiometric displacement transducer (Fernie and Holiday, 1978). The subject's wear an aluminium pad around their waist; a fishing line connects the aluminium pad to the displacement transducer. The transducer records the antero-posterior sway of the subject's. This technique has been used to evaluate the sway patterns of healthy volunteers, below the knee amputees and elderly subjects with a history of falls (Dornan et al, 1978; Fernie et al, 1982). This technique only provides information about antero-posterior sway under static conditions. This technique loads the subject at the waist, which would therefore not be recommended for use with frail subjects. There have been no reported studies regarding the reliability or accuracy of potentiometric displacement transducers. 
Mechanical Ataxia Meters assesses subjects antero-posterior sway by recording the number of rotations of a perforated wheel, which is attached by a taut string to the subject's waist (Wright, 1971). Movements up to 5 degrees are communicated to a double ratchet mechanism, which causes a pointer to rotate over a dial graduated from 0 to 100 . Ataxia meters are available commercially and are commonly found in physiotherapy departments due to the simplicity of their design. Mechanical ataxia meters are used to identify and evaluate subjects with a history of falls (Overstall et al, 1977). However they only measure balance in the anteroposterior direction under static conditions and there have been no reported investigations into the reliability or accuracy of this technique.

Sway Magnetometry evaluates balance by measuring the distance a subject sways in both the antero-posterior and the medio-lateral direction using two channels; each channel having one transmitter coil and one receiver coil. The transmitter coil of each channel produces a magnetic field, and the strength of the magnetic field picked up by the receiver coil is used to determine the distance between the two coils. The transmitter coil of each channel is secured to a vertical non-metallic surface while the receiver coils are attached to the subject's waist using a belt (Dean et al, 1986). The sway of the subject causes the magnetic field to vary; this change in magnetic field is used to measure the displacement of the subject's sway. Sway magnetometry has been used to evaluate the sway patterns of healthy subjects from 20 to 60 years. Sway magnetometry has been found to have a test-retest reliability of < 14\% for daily measurements (Elliott and Murray, 1998).

Multi-sensor polymer insoles involve the measurement of the pressure distribution under the feet of standing subject's (Pedotti et al, 1984). It is primarily used for assessing the symmetry of standing balance in subjects who have suffered a stroke. There have been no reported investigations into the reliability or accuracy of this technique.

Three-dimensional video analysis of balance evaluates three-dimensional standing balance by using three video cameras and a force platform (Newton and Neal, 1994). Reflective markers are attached to the subjects and they highlight 24 
body landmarks. Then three-dimensional photogrammetric techniques are used to recreate the three-dimensional co-ordinates of the subjects' landmarks while the location of the line of gravity is determined from the force platform. This technique was found to be reliable $(\mathrm{p}<0.01)$ and that very small deviations of spinal alignment could be detected (Newton and Neal, 1994). However, this technique is time consuming to set up and is best suited for use in research laboratories.

Static Force Platform measure the displacement of a subject's centre of pressure while standing still using three or four force transducers (Murray et al, 1975). Static force platforms are available commercially and are used in both physiotherapy and audiology departments due to the simplicity of their design. Static force platforms have been used to evaluate subjects with balance disorders as a result of neurological damage; elderly subject's with a history of falls and balance disorders caused by the ageing process. Static force platforms have been found to have a testretest reliability of ICC>0.6 (Levine et al, 1996; Benvenuti et al, 1999).

Muscle Electrodes have been used to assess the contribution of the major muscle groups to the postural control system (Signorile et al, 1995). Other studies have involved the use of muscle electrodes in conjunction with video-analysis of body movements, while walking on a treadmill moving at different frequencies (Berger et al, 1995).

The assessment of the vestibular systems contribution to the postural control system has been evaluated using harmonic acceleration of the horizontal canal within the vestibular system and rotational tests. The response of the vestibular system was measured using a head and eye tracking system which measured the vestibular-ocularreflex (Rubin, 1984; Jones et al, 1984; Allison et al, 1996).

Dynamic force platforms measure the displacement of a subject's centre of pressure under dynamic conditions using four force transducers and a displacement motor for displacing the support surface of the force platform. Dynamic force platforms are used to assess the contribution of the visual system, the somatosensory system and the vestibular system (Furman, 1994, Ishida and Fukuoka, 1997). They 
are available commercially and are used in both physiotherapy and audiology departments due to the simplicity of their design. Dynamic force platforms have been used to evaluate subjects with balance disorders as a result of neurological damage or vestibular damage; elderly subject's with a history of falls and balance disorders caused by the ageing process. They have been found to have a test-retest reliability of ICC $>0.6$ (Ford-Smith et al, 1995; Liston et al, 1996).

Other physiological balance assessment tests include Hall effect transducers (Weinhoffer et al, 1993), an accelerometer (Kamen et al, 1998), and a multi-channel piezoresistive accelerometer (Farhrenberg et al, 1997).

The direct physiological balance assessment tests, such as Potentiometric displacement transducers, are reported to be sensitive enough to detect small changes in the subject's ability to balance. However, these methods are often criticised as being time consuming to set-up, sometimes burdensome for the patient and most importantly they assess balance under static conditions rather than dynamic conditions which yields more information about the subject's ability to maintain balance. Therefore, these tests are more suited to research laboratories than to busy physiotherapy or audiology departments. Most indirect physiological balance assessment tests, such as harmonic acceleration, are only able to provide information on one component of the postural control system with the exception of dynamic force platforms. Dynamic force platforms are sensitive to small changes in subject's ability to balance and can successfully simulate dynamic situations through which the identification of most balance disorders can be made (Furman, 1994). There is however, a lack of calibration and performance data associated with dynamic force platforms which make it difficult to use them for sequential or comparative work (Andres and Anderson, 1980). Current studies are redressing this problem (Bobbert and Schamhardt, 1990; Mita et al, 1993; Hall et al, 1996; Browne and O'Hare, 2000(b)).

\section{Conclusions}

Functional assessments of balance provide information about the subject's ability to function independently and are useful as screening tools for identifying subjects in 
need of a more thorough evaluation of balance. However, when further information is required a balance assessment test, which monitors small changes in a subject's ability to balance, is needed. When choosing from the numerous balance assessment tests available the burden on which the test places on the subject and the need for a dynamic test should be considered. The most favourable test for measuring balance appears to be a dynamic force platform, which provides information about several components of the postural control system under dynamic conditions while detecting small changes in a subject's ability to balance. 


\section{References}

Allison RS, Eizenman M, Cheung BS (1996) 'Combined Head and Eye Tracking System for Dynamic Testing of the Vestibular System', IEEE Transactions on Biomedical Engineering, 43, pp 1073 - 1081.

Andres RO, Anderson DJ (1980) 'Designing a Better Postural Control Measurement System', American Journal of Otolaryngology, 1, pp 197 - 205.

Balogun J, Akindale K, Nihinola J, Marzouk O (1994) 'Age Related Changes in Balance Performance', Disability and Rehabilitation, 16, pp 58-62.

Baloh RW, Jacobson KM, Beykirch K, Honrubia V (1998) 'Static and Dynamic Posturography in Patients with Vestibular and Cerebellar Lesions', Arch Neurology, 55, pp 649 - 654.

Baloh R, Corona S, Jacobson K, Enrietto J, Bell T (1998) 'A Prospective Study of Posturography in Normal Older People', J. Am. Geriatr Soc., 46, pp 438 - 443.

Berg K (1989) 'Balance and its Measure in the Elderly: A Review', Physiotherapy Canada, 41, pp 240245 .

Berg KO, Maki BE, Williams JI, Holliday PJ, Wood-Dauphinee SL (1992) 'Clinical and Laboratory Measures of Postural Balance in an Elderly Population', Arch Phys Med Rehabil, 73, pp 1073-1080.

Berg K, Norman KE (1996) 'Functional Assessment of Balance and Gait', Gait and Balance Disorders, 12, pp 705-723.

Berger W, Trippel M, Assaiante C, Zijlstra W, Dietz V (1995) 'Developmental Aspects of Equilibrium Control During Stance: a Kinematic and EMG Study, Gait and Posture, 3, pp 149-155.

Dean EM, Griffiths CJ, Murray A (1986) 'Stability of the Human Body Investigation by Sway Magnetometry', Journal of Medical Engineering \& Technology, 10, p 126-130.

Duncan P, Weiner D, Chandler J, Studenski S (1990) 'Functional Reach: A New Clinical Measure of Balance', Journal of Gerontology, 45, pp M192 - 197.

Duncan P, Studenski s, Chandler J, Prescott B (1992) 'Functional Reach: Predictive Validity in a Sample of Elderly Male Veterans', J Gerontol, 47, pp93-98. 
Elliott C, Murray A (1998) 'Repeatability of Body Sway Measurements; Day-to-Day Variation Measured by Sway Magnetometry', Physiol. Meas, 19, pp 159-164.

Fahrenberg J, Foerster F, Smeja M (1997) 'Assessment of Posture and Motion by Multichannel Piezoresistive Accelerometer Recordings' Psychophysiology, 34, pp 607-612.

Fernie G, Holiday P (1978) 'Postural Sway in Amputees and Normal Subjects', The Journal of Bone and Joint Surgery, 60-A, pp 895-898.

Fugl-Meyer AR, Jaasko L, Leyman I, Olsson S, Steglind S (1975) 'The Post-Stroke Hemiplegic Patient: A Method for Evaluation of Physical Performance, Scand J. Reh. Med., 7, pp 13-31.

Furman JM (1994) 'Posturography: Uses and Limitations', Balliere's Clinical Neurology, 3, pp 501513.

Gehlsen GM, Whaley MH (1990) 'Falls in the Elderly: Part II, Balance, Strength, and Flexibility', Arch Phys Med Rehabil, 71, pp 739-741.

Hill K, Vandervoort A, Kramer J (1990) 'Reproducibility of Performance on a Test of Postural Responses in Healthy Elderly Females', Physiotherapy Canada, 42, pp 61 - 67.

Ishida A, Fukuoka Y (1997) 'Analysis of the Posture Control System Under Fixed and SwayReferenced Support Conditions', IEEE Transactions on Biomechanical Engineering, 44, pp 331-335.

Jebsen R, Taylor N, Trieschmann R, Trotter M, Howard L (1969) ‘An Objective and Standardised Test of Hand Function', Arch Phys Med Rehabil, 50, pp 311.

Jones GM, Berthoz A, Segal B (1984) 'Adaptive Modification of the Vestibulo-Occular reflex By Mental Effort in Darkness', Exp. Brain Research, 56, pp 149-153.

Kamen G, Patten C, Du C, Sison S (1998) 'An Accelerometry-Based System for the Assessment of Balance and Postural Sway', Gerontology, 44, pp 40 - 45.

Kapteyn TS (1972) 'The Stabiliogram; Measurement Techniques', Agressologie, 13(C), pp 75-78.

Kapteyn TS, Bles W, Njiokiktjien Ch, Kodde L, Massen Ch, Mol JMF (1983) 'Standardisation in Platform Stabiliometry being a Part of Posturography', Agressologie, 24, pp 321 - 326. 
Katz S, Ford A, Maskomitz R, Jackson B, Jaffee M (1963) 'Studies of Illness in the Aged. The Index of ADL: A Standardised Measure of Biological and Psychosocial Function', JAMA, 185, pp 74.

Mahoney F, Barthel D (1965) 'Functional Evaluation: The Barthel Index, Maryland State Med J., 14, pp 61.

Murray M, Seireg A, Sepic S (1975) 'Normal Postural Stability and Steadiness: Quantitative Assessment', The Journal of Bone and Joint Surgery, 57A, pp 510 - 516.

Newton RU, Neal RJ (1994) 'Three-dimensional quantification of Human Standing Posture', Gait and Posture, 2, pp 205-212.

Njiokiktjien Ch (1980) 'The Current State of Posturography in Neurology’, Agressologie, 21 pp 31 33.

Okubo J (1980) ‘The Review of Posturography in Japan', Agressologie, 21, pp 3 - 24.

Pedotti A, Assente R, Fusi G, De Rossi D, Dario P, Domenici C (1984) 'Multisensor Piezoelectric Polymer Insole for Pedobarography', Ferroelectrics, 60, pp 163-174.

Romberg MH (1853) 'Manual of Nervous Diseases of Man', Sydenham Society, pp. 395-401.

Rubin W (1984) ‘Harmonic Acceleration as a Measure of Vestibular Compensation', Acta

Otolaryngol, 406, pp 137-139.

Signorile JF, Kacsik D, Perry A, Williams R, Lowensteyn I, Digel S, Caruso J, LeBlanc WG (1995)

'The Effect of Knee and Foot Position on the Electromyographical Activity of the Superficial Quadriceps', Research Study, 22, pp 2-9.

Starck J, Pyykko I, Aalto H, Pekkarinen J (1993) 'Measurement of Postural Stability: Development of a Force Platform and Some Excitation Systems', Medical Progress through Technology, 18, pp 209 215 .

Tangeman PT, Banaitis DA, Williams AK (1990) Arch Phys Med Rehabil, 71, pp 876-880.

Tell GS, Lefkowitz DS, Diehr P, Elster AD (1998) 'Relationship Between Balance and Abnormalities in Cerebral Magnetic Resonance Imaging in Older Adults', Arch Neurology, 55, pp 73-79. 
Tinetti ME, Williams TF, Mayewski R (1986) 'Fall Risk Index for Elderly Patients Based on the Number of Chronic Disabilities', The American Journal of Medicine, 80, pp 429-434.

Weinhoffer SL, Barnes SZ, Berme N (1993) 'Measurement of Angular Displacements Using Hall Effect Transducers', Journal of Biomechanics, 26, pp 609-612.

Winter DA (1995) 'Human Balance and Posture Control during Standing and Walking', Gait \& Posture, 3, pp $193-214$.

Wright BM (1971) ‘A Simple Ataxia-Meter', Journal of Physiology, 218, pp 27P-28P. 